\title{
Adrenal Incidentaloma In Patient with Bilateral Nephroli- thiasis and Infectef Right Kidney Cyst
}

\author{
Hermina Novida ${ }^{*}$, Kholidatul Husna ${ }^{2}$ \\ ${ }^{1}$ Division Endocrinology and Metabolic, Department of Internal Medicine, Faculty of Medicine, Universitas Airlangga - Dr. \\ Soetomo General Hospital Surabaya, Indonesia. \\ ${ }^{2}$ Department of Internal Medicine, Faculty of Medicine, Universitas Airlangga - Dr. Soetomo General Hospital Surabaya, \\ Indonesia.
}

\begin{abstract}
A B S T R A C T
Adrenal incidentaloma (AI) is a rare case, with a prevalence of 3-7\% in the general population. We report a case of a 66 year old female, presented with the history of bilateral flank pain. The patient was performed urologic evaluation due to suspicion of right perirenal abscess and left kidney tumor, and from abdominal CT scan it was found suprarenal mass. There were no signs and symptoms of hormonal hyperfunction. Radiological evaluation in the patient showed the present of malignant lesion. Therefore, adrenalectomy was planned. Before undergoing adrenalectomy, the patient had passed away 6 days after first surgery (right pyelolitotomy and unroofing cyst), with septic shock suspected as cause of death due to hospital-acquired pneumonia.
\end{abstract}

Keywords:Adrenal incidentaloma, non-functional mass, malignant lesion

Correspondence: Hermina Novida

E-mail: hermina-n@fk.unair.ac.id

Article history: • Received 24 August $2020 \bullet$ Received in revised form 29 August $2020 \bullet$ Accepted 31 August 2020

\section{INTRODUCTION}

As the consequence of the development of modern imaging technology, the discovery of an incidentally found adrenal mass (or incidentaloma) has been increased. Adrenal incidentaloma (AI) is a rare case, with a prevalence of $3-7 \%$ in the general population. The prevalence of AI has been reported as $6 \%$ in autopsy series and $4 \%$ in radiologic series. The incidence increases with age, it was reported less than $1 \%$ in patients younger than 30 years old and up to $7 \%$ in patients over 70 years old. Females suffer from AI slightly more often than males (Bovio et al., 2006; Young $\mathrm{Jr}, 2007$ ). About $80 \%$ of AI are non-functional adenomas, in patients without history of malignancy $(70-94 \%)$. The incidence of adrenocortical carcinoma or metastasis is about 2-3\%, while 6-7\% are myelolipoma or benign cyst (Bovio et al., 2006; Zeiger et al., 2011). Some adrenal masses do not cause health problems, but in few cases it can cause serious illness. We report a case of AI, in patient with bilateral nephrolithiasis and infected right kidney cysts, with incidentally found left adrenal mass.

\section{CASE REPORT}

A 66 year old female, married, a Javanese, a farmer from Nganjuk came to emergency room of Dr. Soetomo Hospital with chief complaint of flank pain. Bilateral flank pain was complained since 3 months before admission and it was getting worse. Pain referred to the front of flank and colic. The urination was not smooth, painful, bloody, but it never contained sand or stone. The patient never accommodated how much urine she had per day. There were no complaints of nausea, vomiting, fever, shortness of breath, or mass in her stomach. The defecation was normal. There were no complaints of weight loss, frequent urination, easily hungry or thirsty. Patient had been diagnosed with kidney stones since 3 months ago, and had undergone placement of DJ stent at Jombang General Hospital on October 3rd 2016. She also complained the mass out of the vagina since 10 years ago. She had done the installation of ring twice by obstetrician at Jombang General Hospital but they failed, so she was referred to Dr. Soetomo General Hospital. From obgyn clinic, she was consulted to nephrology clinic due to high potassium, and then the patient was sent to the emergency room. She had no history of cancer, diabetes or high blood pressure. The older siblings suffer urinary stones. There was no family history of cancer, diabetes or high blood pressure. The patient was a farmer, but she had not worked for long time. She had regular menstruation, and had been menopause since 7 years ago. She had four children with normal delivery.

The physical examination showed the general condition was moderate illness, compos mentis (GCS 4-5-6) with blood pressure 110/80 $\mathrm{mmHg}$, heart rate $98 \mathrm{x} /$ minute (regular and adequate pulse), respiratory rate $20 \mathrm{x} /$ minute, and axillary temperature $36.2^{\circ} \mathrm{C}$. Head and neck examination showed there was no anemia, jaundice, cyanosis or dyspnea, no lymph nodes enlargement, and JVP was not increased. Chest examination showed there 
was symmetrical chest motion, no retraction, and single S1 S2 heart sound without any additional sound. Respiratory sound was vesicular in both lungs, neither wheezing nor rhonchi. Abdominal examination showed normal bowel sounds, no enlargement of the liver or lien, no palpable mass; no shifting dullness nor costovertebral angle tenderness. Suprapubic: bladder was empty. Genitalia examination showed there was no fluor or fluxus, portio in front of vagina, there was $15 \times 15 \mathrm{~cm}$ mass. From urine catheter, urine production was $1100 \mathrm{cc}$ per day, yellow and clear. Extremities_examination showed warm perfusion and there was no edema.

Other investigations from Jombang General Hospital, abdominal x-ray on August $3^{\text {rd }}$ 2016: right nephrolithiasis and left ureterolithiasis; abdominal ultrasound on August $21^{\text {th }}$ 2016: bilateral hydronephrosis grade 2-3 with right nephrolithiasis. From obgyn clinic at Dr. Soetomo General Hospital, chest $\mathrm{x}$-ray on October $26^{\text {th }} 2016$ : heart and lung within normal limit; laboratory results on October $26^{\text {th }} 2016$ : $\mathrm{Hb} 12.4 \mathrm{~g} / \mathrm{dl}$; leukocyte $14,520 / \mu \mathrm{L}$; granulocyte $83.1 \%$; platelet $264,000 / \mu \mathrm{L}$; random plasma glucose (RPG) 143 $\mathrm{mg} / \mathrm{dl}$; AST $16 \mathrm{U} / \mathrm{L}$; ALT $28 \mathrm{U} / \mathrm{L}$; albumin $3.4 \mathrm{~g} / \mathrm{dl}$; BUN $31 \mathrm{mg} / \mathrm{dl}$; serum creatinine $1.56 \mathrm{mg} / \mathrm{dl}$; Na $129 \mathrm{mmol} / \mathrm{l}$; K 6. $3 \mathrm{mmol} / \mathrm{l}$; $\mathrm{Cl} 95 \mathrm{mmol} / \mathrm{l}$ and non-reactive HBsAg.

Laboratory examination from the emergency room of Dr. Soetomo General Hospital on October $27^{\text {th }} 2016$ :

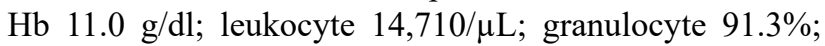
platelet 209,000/ $\mu \mathrm{L}$; RPG $288 \mathrm{mg} / \mathrm{dl}$; AST $17 \mathrm{U} / \mathrm{L}$; ALT $26 \mathrm{U} / \mathrm{L} ;$ BUN $31 \mathrm{mg} / \mathrm{dl}$; serum creatinine $1.44 \mathrm{mg} / \mathrm{dl}$; CRP $6.36 \mathrm{mg} / \mathrm{L}$; Na $132 \mathrm{mmol} / \mathrm{l}$; K $5.3 \mathrm{mmol} / \mathrm{l}$; Cl 103 $\mathrm{mmol} / \mathrm{l}$. Urinalysis: yellow, turbid; BJ 1.010; pH 6. 0; prot (-); gluc (-); uro $3.2 \mathrm{mmol} / \mathrm{L}$; bil (-); nit (-); leu (+4); bld (-); leut $>100 / \mathrm{hpf}$; ery $0-2 / \mathrm{hpf}$; low epit; crystal (-); cylinder (-); bacteri (-). Blood gas analysis: $\mathrm{pH}$ 7. 36; $\mathrm{PCO}_{2} 33$ $\mathrm{mmHg}$; $\mathrm{PO} 286 \mathrm{mmHg} ; \mathrm{HCO}_{3} 21 \mathrm{mmol} / \mathrm{l}$; $\mathrm{BE}-2.8, \mathrm{SO}_{2}$ 97\%. ECG: sinus rhythm $85 \mathrm{x} /$ minute, normal axis. Chest $\mathrm{x}$-ray was normal. Abdominal x-ray: suspicious of multiple opaque stones of right kidney with the largest size $+/-2 \mathrm{x}$ $2.2 \mathrm{~cm}$ and opaque stone of left kidney with size $+/-1.6 \mathrm{x}$ $1.8 \mathrm{~cm}$; visible of bilateral DJ stent. Abdominal ultrasound: left nephrolithiasis with size $+/-1.2 \mathrm{~cm}$ and local caliectasis of upper and lower pole, and multiple right nephrolithiasis with the largest size $+/-2.3 \mathrm{~cm}$ and mild caliectasis of upper pole, bilateral parenchymal kidney disease; anechoic lesion with internal echo in right kidney DD: 1. Urinoma, 2. Complex cyst, 3. Perirenal abscess; solid lesion in left kidney with size $+/-4.7$ x $4.2 \mathrm{~cm}$.

Interdepartmental consultations, 1) Urology: the patient was diagnosed with bilateral nephrolithiasis post bilateral URS DJ stent + suspicious of right perirenal abscess + suspicious of left kidney tumor, suggested to perform abdominal CT scan with contras; 2) Obgyn: the patient was diagnosed with uterine prolapse grades III, the patient was planned to undergo trans abdominal hysterectomy with anterior-posterior colporrhaphy, elective surgery from obgyn clinic.

Based on anamnesis, physical, laboratory \& radiology examination, the patient was diagnosed as bilateral nephrolithiasis on bilateral URS DJ stent + suspicious of right perirenal abscess + suspicious of left kidney tumor + suspicious of urinary tract infection (UTI) + acute kidney injury + hyperglycemia + uterine prolapse grades III. The patient was planned to perform abdominal CT scan, fasting plasma glucose (FPG), 2 hours plasma glucose (2h-PG), HbA1C, calcium (ca), phosphate (p), uric acid, blood and urine culture. Blood glucose was regulated with insulin correction 4 unit intravenous injection. The patient was given $\mathrm{B} 2$ diet 2,100 $\mathrm{kcal} /$ day, fluid balance $\mathrm{I}=\mathrm{O}+500$, $\mathrm{NaCl}$ 0. 9\% infusion 1,000 ml/day, Ceftriaxone 1 gram/12 $\mathrm{h}$ intravenous injection. The patient was monitored for complaint, vital signs, and urine production/day.

\section{Clinical Progression}

On the $6^{\text {th }}$ day of admission, flank pain became better. GCS 456 , with blood pressure $110 / 70 \mathrm{mmHg}$, heart rate $88 \mathrm{x} /$ minute (regular and adequate pulse), respiratory rate $20 \mathrm{x} /$ minute, and axillary temperature $36.2^{\circ} \mathrm{C}$. Urine production was $1,500 \mathrm{ml} / 24 \mathrm{~h}$. Laboratory finding: leukocyte $9,600 /$ $\mu \mathrm{L}$; granulocyte $80.1 \%$; FPG $73 \mathrm{mg} / \mathrm{dl}$; 2-h PG $76 \mathrm{mg} / \mathrm{dl}$; HBA1C 5.8\%, BUN $19 \mathrm{mg} / \mathrm{dl}$; serum creatinine $1.13 \mathrm{mg} / \mathrm{dl}$; $\mathrm{K} 3.7 \mathrm{mmol} / \mathrm{l}$; Ca $8.5 \mathrm{mg} / \mathrm{dl}$, P $2.8 \mathrm{mg} / \mathrm{dl}$, uric acid $5.0 \mathrm{mg} /$ dl. Abdominal CT scan result showed solid mass (38 HU), irregular shape with smooth margins size $+/-5.2 \times 4.8$ x 5.9 $\mathrm{cm}$ in left suprarenal, heterogeneous texture and attenuation (density) on contrast showed contrast enhancement (68 $\mathrm{HU}$ ), the mass attached with upper left kidney; right perinephric abscess; bilateral multiple nephrolithiasis (biggest size: right kidney $+/-1.56 \mathrm{~cm}$ and left kidney $+/$ $1.6 \mathrm{~cm}$ ) with mild bilateral hydronephrosis. The patient was diagnosed with multiple bilateral nephrolithiasis + mild bilateral hydronephrosis + on bilateral URS DJ stent + right perinephric abscess + suspicious of left adrenal tumor. The patient was transferred to the urology surgery ward.

On the $11^{\text {th }}$ day of admission, there was no headache, fatigue, proximal muscle weakness, easy bruisability, virilization, anxiety attacks, sweating, weight gain, or weight loss. GCS 456, with blood pressure 130/80 $\mathrm{mmHg}$, heart rate 90x/minute (regular and adequate pulse), respiratory rate $20 \mathrm{x} /$ minute, and axillary temperature $36.4^{\circ} \mathrm{C}$. The patient's body weight was $60 \mathrm{~kg}$, height $160 \mathrm{~cm}$, with body mass index was $23.44 \mathrm{~kg} / \mathrm{m} 2$. There were no moon face, buffalo hump, and striae. Urine production was $1,600 \mathrm{ml} / 24 \mathrm{~h}$. Laboratory finding: serum cortisol $44.55 \mu \mathrm{g} / \mathrm{dl}$. The patient was diagnosed with non-functional left adrenal incidentaloma. She was planned to do 1-mg overnight dexamethasone suppression test.

On the $17^{\text {th }}$ day of admission, the patient had no complained. GCS 456, with blood pressure 120/80 $\mathrm{mmHg}$, heart rate $86 \mathrm{x} /$ minute (regular and adequate pulse), respiratory rate $20 \mathrm{x} /$ minute, and axillary temperature $36.7^{\circ} \mathrm{C}$. Urine production was $2,000 \mathrm{ml} / 24 \mathrm{~h}$. Laboratory finding: serum cortisol 51. $41 \mu \mathrm{g} / \mathrm{dl}$ (normal range: 4.3 22.40), АCTH $<10$ (normal range: $6-46 \mathrm{pg} / \mathrm{ml}$ ). Urine culture result: Enterococcus faecalis with colony count $\geq 105 \mathrm{CFU} / \mathrm{ml}$, sensitive for ampicillin sulbactam and chloramphenicol, ceftriaxone was intermediate. Blood culture was sterile. The patient was planned to do surgery in two steps: I. Drainage for right perinephric abscess and right pyelolithotomy (to take the stone on upper pole of right kidney); II. Left adrenalectomy and left pyelolithotomy.

On the 19th day of admission, the patient was operated. From operation report there was no perirenal abscess, but obtained infected kidney cyst sized $5 \times 5 \mathrm{~cm}$ 
and contained pus, unroofing cyst was performed. From right pyelolithotomy, there was stone sized $3 \times 3 \mathrm{~cm}$, then removing the stone and seconder stone in upper and lower pole, DJ stent was reinserted and had been drained. The patient complained pain in post op area, coughing but no fever. General condition was weak, GCS 456, with blood pressure 120/80 $\mathrm{mmHg}$, heart rate $96 \mathrm{x} /$ minute (regular and adequate pulse), respiratory rate $20 \mathrm{x} /$ minute, and axillary temperature $36.6^{\circ} \mathrm{C}$. Respiratory sound was vesicular in both lungs, neither wheezing nor rhonchi. Urine production was $1,500 \mathrm{ml} / 24 \mathrm{~h}$, drain production was $10 \mathrm{ml} / 24 \mathrm{~h}$ and hemorrhagic. Laboratory finding: $\mathrm{Hb} 10.3 \mathrm{~g} / \mathrm{dl}$; leukocyte $7,730 / \mu \mathrm{L}$; granulocyte $69.2 \%$; platelet $196,000 / \mu \mathrm{L}$; RPG $125 \mathrm{mg} / \mathrm{dl}$; albumin $3.0 \mathrm{~g} / \mathrm{dl}$.

On the $22^{\text {th }}$ day of admission, 4 days post op the patient's condition worsened: decreased consciousness, shortness of breath, and fever. GCS 235, with blood pressure $90 / 60 \mathrm{mmHg}$, heart rate $112 \mathrm{x} /$ minute (regular and adequate pulse), respiratory rate $28 \mathrm{x} /$ minute, and axillary temperature $38.9^{\circ} \mathrm{C}$. Respiratory sound was vesicular in both lungs, there was rhonchi but no wheezing. Urine production was $1,500 \mathrm{ml} / 24 \mathrm{~h}$, drain production was 10 $\mathrm{ml} / 24 \mathrm{~h}$ and hemorrhagic. Laboratory finding: $\mathrm{Hb} 10.5$ $\mathrm{g} / \mathrm{dl}$; leukocyte $11,930 / \mu \mathrm{L}$; granulocyte $81 \%$; platelet

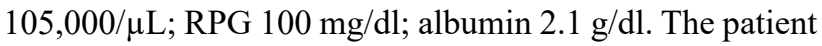
was diagnosed with late onset hospital acquired pneumonia $(\mathrm{HAP})+$ sepsis + post cystectomy and right pyelolithotomy day $4+$ left pyelum stone + post bilateral URS DJ stent + suspicious of non-functional left adrenal tumor + hypoalbuminemia + uterine prolapse grade III. The patient was given enteral nutrition with nasogastric tube $6 \times 50$ cc, fluid balance $\mathrm{I}=\mathrm{O}+500, \mathrm{NaCl} 0.9 \%$ infusion $2,000 \mathrm{ml}$, intravenous levofloxacin $500 \mathrm{mg} / 24 \mathrm{~h}$, Cefoperazon sulbactam $1 \mathrm{~g} / 12 \mathrm{~h}$ and albumin $20 \%$. Then planned blood, sputum and urine culture. Nevertheless, the patient died 2 days later or 6 days after first surgery (pyelolitotomy D and unroofing cyst) with septic shock suspected as cause of death due to late-onset of HAP.

Table 1. Staging of adrenocortical carcinoma and its prognosis

\begin{tabular}{ccc}
\hline Stage & Description & 5 yr survival \\
\hline I & $\begin{array}{c}\text { T1, N0, M0 } \\
\text { (Tumor } \leq 5 \mathrm{~cm})\end{array}$ & $66-82 \%$ \\
\hline II & $\begin{array}{c}\text { T2, N0, M0 } \\
\text { (Tumor }>5 \mathrm{~cm})\end{array}$ & $58-64 \%$ \\
\hline III & $\begin{array}{c}\text { T1-2, N1, M0 (lymph } \\
\text { nodes involvement) }\end{array}$ & 24-50\% \\
& $\begin{array}{c}\text { T3-4, N0, M0 (T3, his- } \\
\text { tologically proven tumor } \\
\text { invasion of surrounding } \\
\text { tissue; T4, tumor invasion } \\
\text { of adjacent organs or ve- } \\
\text { nous tumor thrombus in } \\
\text { vena cava or renal vein) }\end{array}$ \\
\hline IV & $\begin{array}{c}\text { T1-4, N0-1, M1 } \\
\text { (distant metastases) }\end{array}$ \\
\hline
\end{tabular}

\section{DISCUSSION}

Adrenal incidentaloma is a term used in adrenal mass which is accidentally discovered in a series of radiological examination (CT scan/MRI) performed for other reasons (Moreira \& Pow-Sang, 2002; Jain, 2013). Some of the reasons or indications of radiological examination include: abdominal pain, urological complaints, low back pain, trauma, and others (Arnold et al., 2003).

The patient came with flank pain and performed urologic evaluation due to suspicion of right perirenal abscess and left kidney tumor, and from abdominal CT scan it was found suprarenal mass. Thus, it was diagnosed as adrenal incidentaloma.

The most common causes of flank pain are renal diseases such as nephrolithiasis, pyelonephritis, renal abscess/tumors, and others. Extrarenal causes of flank pain are musculoskeletal problems, retroperitoneal abscess and gynecological problems in women. Often, the history and physical examination will greatly narrow the potential diagnosis. The location of the pain can assist in narrowing the differential diagnosis, but the chronological sequence of events in the patient's history is often more important than the pain's location. The character of flank pain is very helpful in determining the cause. Important characteristics include local or referred pain, acute, chronic or recurrent pain, degree of severity, and duration. Associated symptoms such as fever, nausea, and vomiting, often help in making the correct diagnosis. Physical examination includes the patient's general condition, vital signs, abdominal and back examination. Well-selected laboratory and imaging tests will confirm the actual cause (Jacobs DO and W, 2015; Grill, 2016).

The patient came with bilateral flank pain that was colic, and abnormal urination, was diagnosed with kidney stones since 3 months ago, and had undergone placement of DJ stent. Therefore, the most likely cause of flank pain is nephrolithiasis. However, there was no abnormal physical examination found, so laboratory and radiology examinations were needed to confirm the diagnosis. On laboratory examination at Dr. Soetomo General Hospital it found leukocytosis, hyperglycemia, and leukocyturia. The radiology evaluation results: from abdominal x-ray, it suspected opaque stone of bilateral kidney, in which had been installed bilateral DJ stent; abdominal ultrasound showed bilateral nephrolithiasis with mild bilateral hydronephrosis, anechoic lesion with internal echo in the right kidney, and solid lobulated lesion in the left kidney. Thus, the patient was diagnosed with bilateral nephrolithiasis post-bilateral URS DJ stent + suspicious of right perirenal abscess and left kidney tumor.

Perinephric abscess (PNA) is defined as an abscess outside the renal capsule but within Gerota's fascia. They are rare in comparison to other infections involving the genitourinary tract, but they can cause significant morbidity and mortality. Some predisposes to perinephric abscess: urinary tract obstruction or infection, diabetes mellitus, intravenous drugs user, trauma, recent abdominal or urology surgery, and immunodeficiency conditions such as cancer or AIDS. Signs and symptoms of a PNA have a slow onset and are unspecific. Patients usually come with flank pain, 
flank mass, fever and urinary tract complaints. Ultrasound examination may be helpful, but CT scan is the diagnostic test of choice. Broad-spectrum antibiotic therapy is the first step in treatment and should be associated with drainage in the majority of cases. Meanwhile, the kidney tumor is the third largest urinary tract tumors after prostate and bladder tumor. Kidney tumors can be benign or malignant, and may be a primary or secondary tumor due to metastasis. Many factors are suspected to be the cause of kidney tumors. Typical symptoms of kidney tumor are: low back pain, hematuria, and palpable flank mass. A CT scan is the first choice modality for workup of solid masses in the kidneys (Purnomo, 2011).

The patient was suspected right perirenal abscess and left kidney tumor, thus the doctors performed abdominal CT scan to confirm the diagnosis. The results obtained bilateral multiple nephrolithiasis with bilateral mild hydronephrosis, right perinephric abscess, and left suprarenal mass. The discovery of this adrenal mass happened incidentally, thus it was called adrenal incidentaloma.

The adrenal glands (suprarenal glands) are endocrine glands that produce a variety of hormones. They are found above the kidneys. Each gland has an outer cortex which produces steroid hormones and an inner medulla. The adrenal cortex itself is divided into three zones: the outer region is the zona glomerulosa, which produces mineralocorticoids such as aldosterone (regulates blood pressure); the next region is the zona fasciculata, which produces glucocorticoids such as cortisol; and the inner region is the zona reticularis, which produces androgens such as dehydroepiandrosterone (DHEA). Meanwhile, the adrenal medullary secretes epinephrine (adrenaline) and norepinephrine (noradrenaline) that are released when a person is exposed to pressure, such as anger, injury, or fear. Thus, tumors in this area will manifest according to the affected zone. If the adrenocortical tumor is from zona glomerulosa, it will manifest as Conn syndrome (primary hyperaldosteronism). If it is from zona fasciculata, it will manifest as Cushing's syndrome (hypercortisolism). If it is from zona reticularis, it will manifest as virilism (in women) and feminization (in men). Abnormalities in the adrenal medulla are pheochromocytoma or paraganglioma (Adi S and A, 2014;Wibisono S and A, 2015).

If an adrenal tumor is present, it should be evaluated: (1) Is the tumor functional (hormonally active) or nonfunctional? (2) Does it have radiological characteristics that suggest a malignant lesion? and (3) Does the patient have a history of previous malignant lesions?.(Moreira and Pow-Sang, 2002; Mansmann et al., 2004;Copeland, 2007;Jain, 2013) Patients need to undergo a thorough clinical evaluation to exclude a functional tumor. Patients should be tested for evidence of hypercortisolism, aldosteronism (if hypertensive), and the presence of a pheochromocytoma. For patients with hypercortisolism or Cushing syndrome, the investigation should include inquiries about substantial weight gain or development of centripetal obesity, easy bruisability, severe hypertension, diabetes, virilization, proximal muscle weakness, or fatigue. For patients with pheochromocytoma, inquiries should address the development of sudden or severe headache, weight loss, anxiety attacks, sweating, cardiac arrhythmias, or palpitations. For patients with aldosteronism, the clinician should ask about the presence of hypertension, fluid retention, or a history of hypokalemia. The clinician should inquire about history of cancer, recent weight loss, and smoking history, because an adrenal mass may be a metastatic lesion. Physical examination should include measurement of the patient's blood pressure and pulse as well as assessment for evidence of central obesity, ecchymosis, striae, muscle wasting, hirsutism, or other signs of virilization. However, adrenal tumors can also occur without producing hormones (non-functional), so it does not create the clinical manifestations. Furthermore, it should prompt biochemical evaluation. All patients with AI should be screened for the possibility of cortisol excess. The simplest screening test for cortisol secretion from $\mathrm{AI}$ is a $1-\mathrm{mg}$ overnight dexamethasone suppression test. The literature supports that the overnight $1 \mathrm{mg}$ dexamethasone suppression test (DST), sensitivity and specificity $73 \%$ to $100 \%$ and $90 \%$, respectively, appears to be the test of choice to rule out autonomous glucocorticoid production, Cushing's syndrome, or subclinical Cushing's syndrome (sCS). The ultimate cut-off value for $\mathrm{sCS}$ remains to be elucidated, but cut-offs from $50 \mathrm{nmol} / \mathrm{L}$ to $138 \mathrm{nmol} / \mathrm{L}$ have been used to define adrenal autonomy with a lower cut-off increasing the risk of false positives. Patients with hypertension who have a ratio of plasma aldosterone concentration (PAC) (ng/dL) to plasma renin activity (PRA) (ng/mL per hour) of $>20$ while not taking spironolactone and mineralocorticoid receptor blockers, should undergo further assessment for the presence of primary aldosteronism. Finally, elevated plasma free metanephrine and normetanephrine levels and 24-hour total urinary metanephrines and fractionated catecholamine suggest the presence of a pheochromocytoma (Young Jr, 2007; Zeiger et al., 2009; Kapoor et al., 2011;W, 2015).

Hormonal evaluation of adrenal tumor of the patient was performed to know whether the tumor was functional or non-functional. The patient did not complain of headache, fatigue, excess hair growth, excessive sweating, easy bruising, weight gain, or wight loss. She had been menopause and had prior regular menstruation. There was no history of cancer and she did not smoke. Physical examination in this patient, there was no moon face, buffalo hump, or striae. There was neither hypertension nor diabetes. The laboratory test found slightly increased cortisol level and normal ACTH levels. Thus, the patient was diagnosed as non-functional left adrenal tumor.

Adrenal tumors need to be distinguished as malignant or benign tumors from radiological features. Several parameters of adrenal mass from CT scans can be assessed: size of mass, shape, texture, attenuation (density) on unenhanced CT, vascularity on contrast-enhanced CT and rapidity of washout of contrast medium. In some studies, the $4 \mathrm{~cm}$ as cut-off has high sensitivity (93\%) in predicting malignant processes, but has low specificity (42\%) owing to the low prevalence of ACC. Benign mass usually have regular shape with smooth margins, homogenous texture and attenuation (density) on unenhanced CT $\leq 10$ Hounsfield units (HU). A cut-off of $<10 \mathrm{HU}$ of a region over a mass increases the likelihood of adenoma, sensitivity and specificity by $71 \%$ and $98 \%$, respectively. Characteristics 
of malignant processes include size $(>3 \mathrm{~cm})$, attenuation of $>10 \mathrm{HU}$ on unenhanced CT, heterogeneous texture and increased vascularity with decreased contrast washout $<10$ minutes. Fine-needle aspiration biopsy (FNAB) is currently not recommended for the routine workup of AI. The literature shows that approximately $80 \%$ of patients with AI had non-functioning adenoma, 5\% had subclinical Cushing syndrome, $5 \%$ had a pheochromocytoma, $<5 \%$ had an adrenocortical carcinoma (ACC), 2.5\% had a metastatic lesions, and $1 \%$ had an aldosteronoma; the remaining were ganglioneuroma, myelolipoma, or benign cysts (Young Jr, 2007;Zeiger et al., 2009;Kapoor et al., 2011;Mayo-Smith et al., 2017).

The patient was suspected suffering from adrenal mass; therefore, it was needed to asses the characteristics of the mass. The patient did not complain of weight loss, no history of cancer in the patient and her families. Radiological evaluation in the patient, the present of malignant tumor (adrenal carcinoma) was suspected, because of several parameters: solid mass (38 HU), with size more than 4 $\mathrm{cm}$, heterogeneous texture, partial irregular margin, and contrast enhancement (68 HU).

There are several algorithms for adrenal incidentaloma management (Figure $1 \& 2$ ). The initial step is hormonal evaluation, if the result is positive (functional mass) then mass resection is performed. In non-functional mass or negative hormonal confirmation, assess the characteristics of the mass. Any adrenal mass with concerning radiographic characteristics and most lesions $\geq 4 \mathrm{~cm}$ should be resected because of increased risk of adrenal cancer. If the size of mass $<4 \mathrm{~cm}$ with benign characteristics (homogenous, regular borders, $<10 \mathrm{HU}$ without contrast), then hormonal evaluation is performed. If hormonally active, adrenalectomy should be performed. If not active, it needs to have radiographic reevaluation at 3 to 6 months and then annually for 1 to 2 years, and repeat hormonal evaluation annually for 5 years. If mass grows more than $1 \mathrm{~cm}$ or become hormonally active, then adrenalectomy is recommended. Contralateral adrenal is usually suppressed, if postoperatively shows signs of adrenal insufficiency, hormonal replacement therapy with hydrocortisone is required until the conditions improve (Arnold et al., 2003;Zeiger et al., 2009; Kapoor et al., 2011).

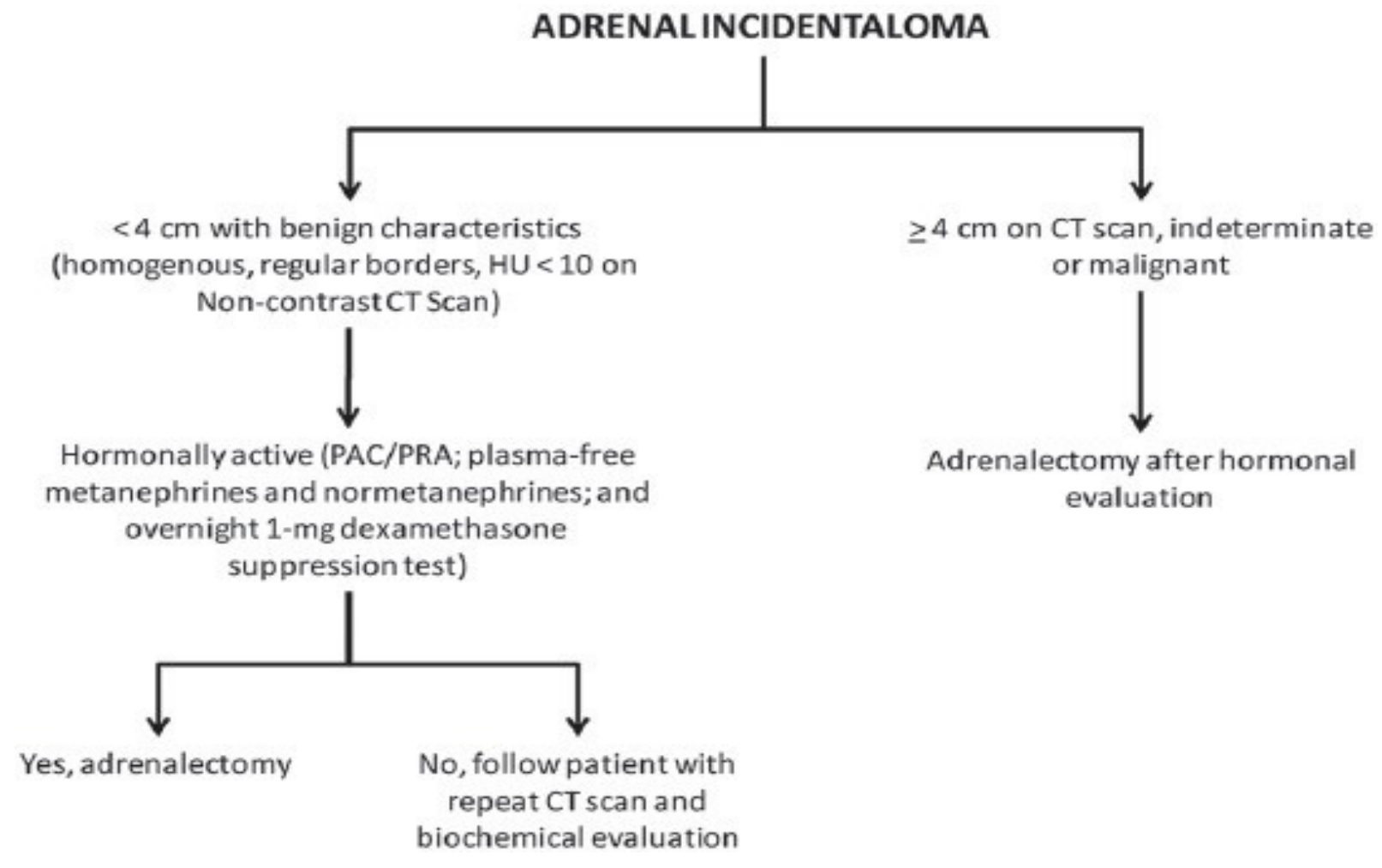

Figure 1. The American Association of Clinical Endocrinologists (AACE) guideline for adrenal incidentaloma. $\mathrm{CT}=$ computed tomographic $\mathrm{HU}=$ Hounsfield units; $\mathrm{PAC}=$ plasma aldosterone concentration; $\mathrm{PRA}=$ plasma renin activity. 


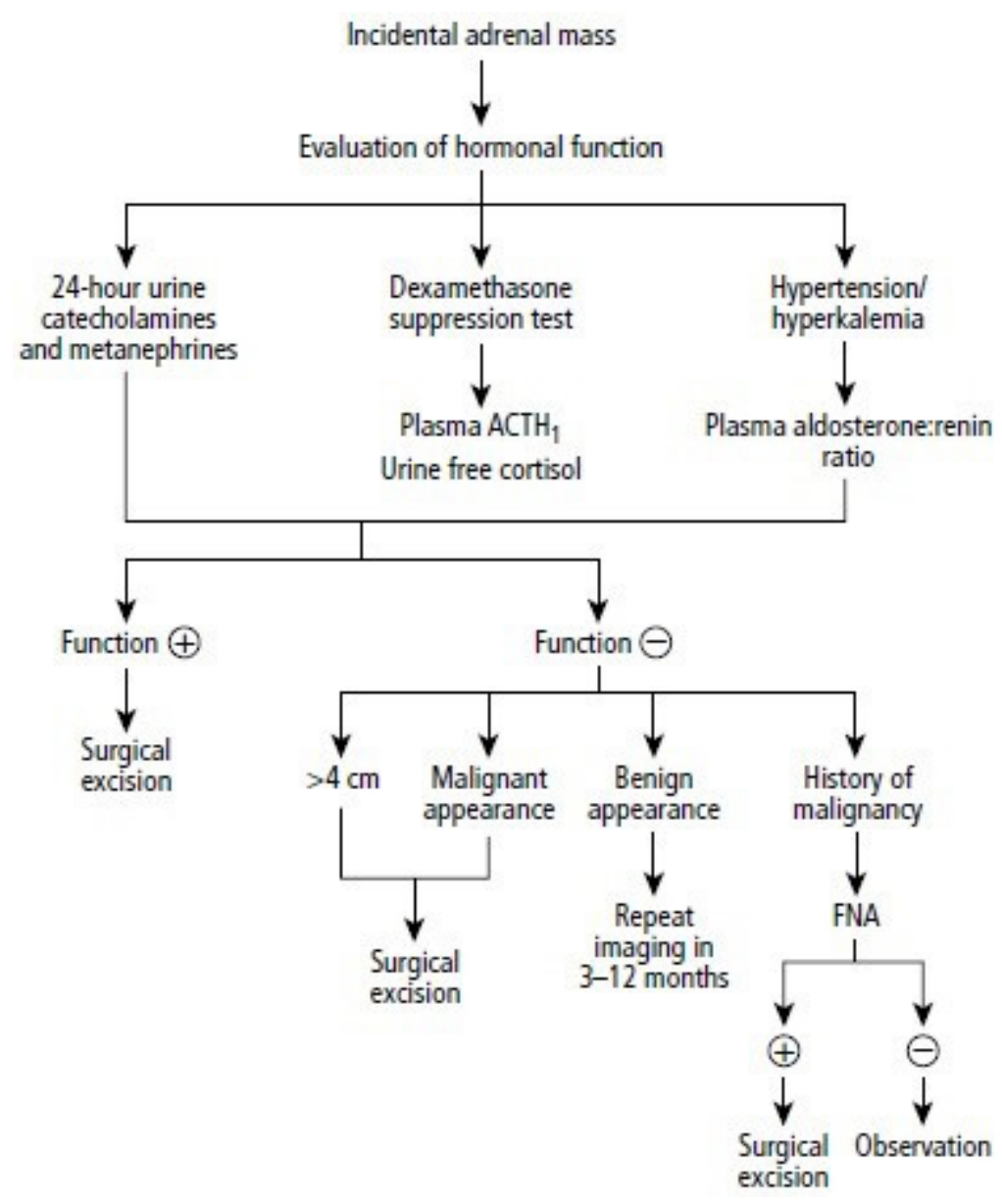

Figure 2. Adrenal incidentaloma algorithm.

$\mathrm{ACTH}=$ adrenocorticotropic hormone; FNA = fine-needle aspiration.

Indications for treatment on urinary tract stones are obstruction (hydroureter or hydronephrosis) or infection (pyonephrosis, urosepsis, renal abscess, perinephric abscess, paranephric abscess, or pyelonephritis). The stone can be removed by non-operative (if the size is $<5 \mathrm{~mm}$ ), or Extracorporeal Shockwave Lithotripsy (ESWL), through endourological action (Percutaneous Nephrolithotripsy/PNL, ureteroscopy or Uretherorenoscopy/URS, Dormia extraction), laparoscopic surgery, or open surgery (pyelolithotomy/ nephrolithotomy, ureterolithotomy). Meanwhile perinephric abscess management is broad-spectrum antibiotic therapy with abscess drainage through open surgery or percutaneous (Purnomo, 2011;M, 2014;GC, 2015).

Evaluation of adrenal mass in the patient showed the present of malignant non-functional mass was suspected. Therefore, mass resection or adrenalectomy was planned. This patient had undergone URS (uretero-renoscopy) and placement bilateral DJ stent in previous hospital because of nephrolithiasis and ureterolithiasis, but the stone was not removed, so there was still a mild residual hydronephrosis with the complaint of flank pain. However, evaluation at Dr. Soetomo General Hospital found bilateral nephrolithiasis on bilateral DJ stent with mild bilateral hydronephrosis, right perinephric abscess, and suspicious of malignant non-functional left adrenal mass. Therefore, 2-phase surgery was planned. Step I: drainage of right perinephric abscess and right pyelolithotomy, step II: left adrenalectomy and pyelolithotomy. The first step surgery reported that there was no right perinephric abscess but an infected right kidney cyst had been found. Therefore, unroofing cyst must be performed and followed with right pyelolithotomy. Before undergoing adrenalectomy, the patient died 6 days after the first surgery.

The prognosis of AI depends on the size of the tumor at diagnosis, type of benign or malignant tumor, patient's age, and hormonal status. Adrenocortical carcinoma is an aggressive tumor with a poor prognosis. The prognosis depends on the stage of cancer at the time it is diagnosed (Table 1). Unfortunately, 60 to $70 \%$ of patients have stage III or IV at the time of diagnosis.(Libé, 2015)

Table 1. Staging of adrenocortical carcinoma and its prognosis

\begin{tabular}{|c|c|c|}
\hline Stage & Description & 5 yr survival \\
\hline I & T1, N0, M0 (Tumor $\leq 5 \mathrm{~cm})$ & $66-82 \%$ \\
\hline II & T2, N0, M0 (Tumor $>5 \mathrm{~cm})$ & $58-64 \%$ \\
\hline III & $\begin{array}{l}\text { T1-2, N1, M0 (lymph nodes } \\
\text { involvement) } \\
\text { T3-4, N0, M0 (T3, histolog- } \\
\text { ically proven tumor invasion } \\
\text { of surrounding tissue; T4, } \\
\text { tumor invasion of adjacent } \\
\text { organs or venous tumor } \\
\text { thrombus in vena cava or re- } \\
\text { nal vein) }\end{array}$ & $24-50 \%$ \\
\hline IV & $\begin{array}{l}\text { T1-4, N0-1, M1 (distant me- } \\
\text { tastases) }\end{array}$ & $0-17 \%$ \\
\hline
\end{tabular}


The patient was diagnosed non-functional malignant tumor, and then a histopathologic biopsy was required to confirm the type of tumor. If the tumor is an adrenocortical carcinoma, the stage was stage II based on several parameters: tumor size $>5 \mathrm{~cm}$, no lymph nodes involvement, and no metastasis based on abdominal CT scan and chest $\mathrm{x}$-ray. Thus, the 5-year survival rate in the patient was 58$64 \%$. However, the patient had passed away because of other causes, with septic shock-suspected as cause of death due to hospital-acquired pneumonia.

\section{CONCLUSION}

Adrenal incidentaloma (AI) is a term used in adrenal mass which is accidentally discovered in a series of radiological examination (CT scan/MRI) performed for other reasons. The patient had been diagnosed with AI due to the discovery of adrenal mass from abdominal CT scan during urological evaluation because of right perirenal abscess and left kidney tumor were suspected. All patients with an AI should be evaluated for possibility of hyperfunctioning or malignant lesion. The evaluation of adrenal mass in the patient showed the present of malignant non-functional mass was suspected. Therefore, mass resection or adrenalectomy was planned. Before undergoing adrenalectomy, the patient had passed away 6 days after first surgery (right pyelolitotomy and unroofing cyst), with septic shock suspected as cause of death due to hospital-acquired pneumonia.

\section{CONFLICT OF INTEREST}

The author declare there is no conflict of interest of this study.

\section{REFERENCES}

Adi S, Pranoto A, 2014. Gangguan Korteks Adrenal. In (Setiati S, Alwi I, Sudoyo AW, Simadibrata M, Setiyohadi B, Syam AF, eds). Buku Ajar Ilmu Penyakit Dalam, 6th Edition, Vol 2, Jakarta: Interna Publishing, 2484-513.

Arlt W, 2015. Disorders of the Adrenal Cortex. In (Longo D1, Kasper DL, Jameson JL, Fauci AS, hauser SL, Loscalzo J, eds). Harrison's Principles of Internal Medicine, 19th edition, Vol 2, United States: Mc-Graw Hill, 2309-28

Arnold DT, Reed JB, Burt K, 2003. Evaluation and management of the incidental adrenal mass.

BUMC PROCEEDINGS, 16: 7-12.

Bovio S, Cataldi A, Reimondo G, Sperone P, Novello S, and Berruti A, 2006. Prevalence of adrenal incidentaloma in a contemporary computerized tomography series. J Endocrinol Invest, 29: 298-302.

Caiafa RO, Izquierdo RS, Villalba LB, Cerqueda MCS, Molina CN, 2011. Diagnosis and management of adrenal incidentaloma: Update in Radiology. Radiología, 53(6): 516- 30.

Copeland MP, 2007. Approach to Incidentally Discovered Adrenal Masses. JCOM, 14(1): 49- 61.
Curhan GC, 2015. Nephrolithiasis. In (Longo Dl, Kasper DL, Jameson JL, Fauci AS, hauser SL, Loscalzo J, eds). Harrison's Principles of Internal Medicine, 19th edition, Vol 2, United States: Mc-Graw Hill, 1866-70.

Griil BJ, 2016. Causes of Flank Pain. Downloaded from www.medscape.com.

Jacobs DO, Silen W, 2015. Abdominal pain. In (Longo D1, Kasper DL, Jameson JL, Fauci AS, hauser SL, Loscalzo J, eds). Harrison's Principles of Internal Medicine, 19th edition, Vol 2, United States: Mc-Graw Hill, 103-7.

Jain SM, 2013. Adrenal incidentaloma: A puzzle for clinician. Indian J Endocr Metab, 17: S59- 63.

Libe R, 2015. Adrenocortical carcinoma (ACC): diagnosis, prognosis, and treatment. Front Cell Dev Biol, 3(45): 1-8.

Kapoor A, Morris T, Rebello R, 2011. Guidelines for the management of the incidentally discovered adrenal mass. Can Urol Assoc J, 5(4): 241-7.

Mansmann G, Lau J, Balk E, Rothberg M, Miyachi Y, and Bornstein SR, 2004. The Clinically Inapparent Adrenal Mass: Update in Diagnosis and Management. Endocr Rev 25(2): 309-40.

Mayo-Smith WW, Song JH, Boland GL, Francis IR, Israel GL, Mazzaglia PJ, Berland LL, and Pandharipande PV, 2017. Management of Incidental Adrenal Masses: A White Paper of the ACR Incidental Findings Committee. J Am Coll Radiol, 1-7.

Moreira SG, Pow-Sang JM, 2002. Evaluation and Management of Adrenal Masses. Cancer control, 9(4): 326-34.

Purnomo BB, 2011. Dasar-dasar Urologi, 3rd Edition, Malang: Sagung Seto, 59-60, 87-102, 247-252.

Sja'bani M, 2014. Batu Saluran Kemih. In (Setiati S, Alwi I, Sudoyo AW, Simadibrata M, Setiyohadi B, Syam AF, eds). Buku Ajar Ilmu Penyakit Dalam, 6th Edition, Vol 2, Jakarta: Interna Publishing, 2121-28.

Wibisono S, Tjokroprawiro A, 2015. Penyakit Kelenjar Adrenal. In (Tjokroprawiro A, Setiawan PB, Effendi C, Santoso D, Soegiarto G, eds). Buku Ajar Ilmu Penyakit Dalam Fakultas Kedokteran Universitas Airlangga Rumah sakit Pendidikan Dr. Soetomo Surabaya, 2nd Edition, Surabaya: Airlangga University Press, 183-91.

Young WF Jr, 2007. The incidentally discovered adrenal mass. N Engl J Med, 356: 601-10. Zeiger MA, Thompson GB, Duh QY, Hamrahian AH, Angelos P, Elaraj D, Fishman E, and

Kharlip J, 2009. The American Association of Clinical Endocrinologists (AACE) and American Association of Endocrine Surgeons (AAES) Medical Guidelines for the Management of Adrenal Incidentalomas. Endoc Pract, 15 (1): 1-20.

Zeiger MA, Siegelman SS, Hamrahian AH, 2011. Medical and surgical evaluation and treatment of adrenal incidentalomas. $\mathrm{J}$ Clin Endocrinol Metab, 96: 2004-15. 